University of Nebraska - Lincoln

DigitalCommons@University of Nebraska - Lincoln

$8-2000$

\title{
Hidden mechanisms generate negative feedbacks in a stochastic model: A comment on Murray
}

Andrew J. Tyre

University of Nebraska-Lincoln, atyre2@unl.edu

Brigitte Tenhumberg

University of Nebraska - Lincoln, btenhumberg2@unl.edu

Follow this and additional works at: https://digitalcommons.unl.edu/bioscifacpub

Part of the Life Sciences Commons

Tyre, Andrew J. and Tenhumberg, Brigitte, "Hidden mechanisms generate negative feedbacks in a stochastic model: A comment on Murray" (2000). Faculty Publications in the Biological Sciences. 210. https://digitalcommons.unl.edu/bioscifacpub/210

This Article is brought to you for free and open access by the Papers in the Biological Sciences at DigitalCommons@University of Nebraska - Lincoln. It has been accepted for inclusion in Faculty Publications in the Biological Sciences by an authorized administrator of DigitalCommons@University of Nebraska - Lincoln. 


\title{
Hidden mechanisms generate negative feedbacks in a stochastic model: A comment on Murray
}

\author{
Andrew J. Tyre and Brigitte Tenhumberg \\ Department of Applied and Molecular Ecology, University of Adelaide, Waite Campus, \\ PMB 1, Glen Osmond, South Australia 5064, Australia \\ Corresponding author - A. J. Tyre
}

\section{Introduction}

The debate between density-dependent and densityindependent population regulation is one of the oldest and most vociferous in ecology. Australian ecologists participated from the beginning (Nicholson 1933; Andrewartha \& Birch 1954). Despite recent efforts to put the debate to rest (Turchin 1995, 1999), there appears little likelihood of either side abandoning the ramparts (Bonsall et al. 1998). Murray (2000; this issue) uses a stochastic simulation model to argue that a significant statistical relationship between birth rate and population size (i.e. density dependence) can arise in the absence of negative feedbacks of population size on fecundity. In this comment we demonstrate that Murray's simulation model has a negative feedback of population density on birth rate embedded in it, so density dependence in birth rate is not a surprising outcome.

We begin with some definitions. Turchin (1995) defines population regulation as the presence of "a long-term stationary probability distribution of population densities." This definition is both more general and more precise than historical definitions that relied on return to a deterministic equilibrium, or floors and ceilings of density. It recognizes that ecological systems are inherently noisy. Not all densities are equally likely, and the further a particular density is from the average, the less likely it is to occur. There is both an "equilibrium," or a population density that is most likely to occur, and soft boundaries beyond which populations do not often go.

We use the following definition of density dependence: a (non)linear relationship between density and realized population growth rate (Turchin 1999). The realized population growth rate, $r$, is $\ln \left(N_{t+1}\right)-\ln \left(N_{t}\right)$, where $N_{t}$ is population size or density at time $t$. Density dependence is a phenomenological relationship that may be present in population time series. Direct density dependence means a decrease in growth rate with increasing density, while inverse density dependence means an increase in growth rate with increasing density. The word non-linear is also important; it means that population growth rate need not always change with density. This is a descriptive definition, and many different ecological mechanisms can lead to such a relationship.

\section{Murray's model}

The main conclusion of Murray (2000; this issue) is that a density-dependent relationship between density and growth rate can arise from a simulation model that has no negative feedbacks from population size on fecundity or survival. The density-dependent relationship in question is a decrease in per capita birth rate with increasing population size (Murray's Figures 3a \& 5a). This argument hinges entirely on whether or not Murray's simulation model has a negative feedback loop of population size on birth rate embedded in it. In this section we develop a deterministic analogue of his stochastic simulation model and demonstrate that it does in fact contain a negative feedback between density and per capita birth rate.

It is important to note that Murray's use of a random number table does not contribute anything special to the simulation model: a random number table is simply a source of random numbers. Murray uses the table by drawing pairs of digits to generate random numbers between 0 and 99 . These numbers have a uniform distribution because a random number table presents single digits in such a way that there is an equal probability of getting each of the 10 digits on the next choice. A random number table that does not have this property is highly suspect. The expected value (i.e. the mean) of a uniform distribution is $(b-a) / 2$ where $a$ is the lower boundary and $b$ the upper boundary. The variance is $\left((b-a)^{2}-1\right) / 12$.

We define $n_{i, t}$ as the number of individuals in the age $i$ cohort at time $t$, and the total population at time $t$ as $N_{t}=\sum n_{i, t}$. Likewise, $s_{i, t}$ is the number of survivors from the age $i$ cohort at the end of time $t$, and $S_{t}=\sum s_{i, t} / N_{t}$ is the proportion of the total population that survives to time $t+1$. Where feasible, we confirm with standard sta- 
tistical tests (Sokal \& Rohlf 1981) that the predictions of our deterministic, analytical model match Murray's simulation using the data in his Table 1.

Murray's first assumption is "the number of individuals in a cohort decreases in time." Therefore, the number of survivors in cohort $i$ from $t$ to $t+1, s_{i, t^{\prime}}$ is uniformly distributed between 0 and $n_{i, t-1}$. Survival is commonly expressed as a proportion, and the proportion surviving (obtained by dividing the number surviving by the cohort size) will always be greater than or equal to 0 and less than 1 . As the distribution of the number of survivors is perfectly uniform the expected value would be just less than 0.5 . For example, if a cohort has 32 individuals, then the number of survivors is uniformly distributed between 0 and 31 , and 31/2 = 15.5 individuals will survive on average. This mathematical interpretation of Murray's first assumption is supported by his plots of the per capita death rate against population size (Murray's Figures 3b \& 5b). In both cases the slopes are not significantly different from 0 (statistics in Murray's paper), and the intercepts are near 0.5. It is not easy to predict the variance in survival, because that will depend on the size of the cohorts making up the population at any time step.

Murray's second assumption is "the initial size of a cohort is less than 100." In our terms, this means that the recruitment into each new cohort has a uniform distribution between 0 and 99. The expected number of new recruits each year is 49.5 , and the variance will be 833.25 . The average recruitment is 52 and the variance is 557 in Murray's 15 years simulation. These values are not significantly different from our theoretical expectations for a uniform distribution $\left(t_{14}=0.38, P=0.7\right.$, and $\chi_{14}^{2}=9.4, P$ $=0.81$, respectively).

In Murray's simulation model, the population $N$ at time $t+1$ is equal to the survivors from time $t$ plus the new recruits. Because there is no difference between individuals of any age class (they all have the same average probability of survival), Murray's model can be rewritten as a single difference equation:

$$
N_{t+1}=S \cdot N_{t}+F
$$

where $N$ is the population size, $S$ is the average annual survival as a proportion, and $F$ is the average annual recruitment. By setting $N_{t+1}=N_{t}=N^{*}$ and rearranging, we get the equilibrium value

$$
N^{*}=\frac{F}{1-S}
$$

which using $F=49.5$ and $S=0.5$ gives $N^{*}=99$. This is not significantly different from the average population size of 105 in Murray's 15 years simulation $\left(t_{14}=0.66, P=\right.$ $0.51)$. His average population size of 96 for the 100 years simulation is even closer to the predicted equilibrium.

Equation 1 is a deterministic model and therefore always predicts the same value for $N_{t+1}$, given a particu- lar $N_{t}$. Murray's simulation model is stochastic, and so a particular population size leads to a distribution of outcomes. For example, $N_{0}=106$ changes to $N_{1}=68$, while $N_{12}=106$ changes to $N_{13}=85$. The expected value from Equation 1 in both cases is 102.5. The best way to confirm that Equation 1 is a good approximation of Murray's simulation model is to compare the predicted change for each population size with the actual simulated change; if Equation 1 is a good approximation there will be a significant correlation (Figure 1; Pearson $r=0.56, P=0.03$ ). Equation 1 correctly predicts the direction of the change in population size in 10 out of 14 of the observations. From this point we will proceed assuming we have demonstrated that Equation 1 contains the essential dynamic features of Murray's simulation model.

We rearrange Equation 1 to provide the realized population growth rate (Appendix):

$$
r=\ln N_{t+1}-\ln N_{t}=\ln \left(S+\frac{F}{N_{t}}\right)
$$

Equation 3 explains quite clearly why the per capita birth rate decreases as a function of density while the per capita survival rate does not (Murray's Figures 3 \& 5). The growth rate of the population is the sum of survival rate and birth rate terms. The birth rate declines proportional to the reciprocal of population density. The reciprocal shape of the per capita birth rate described in Equation 3 is clearly observable in Murray's Figure $5 \mathrm{a}$, despite having a straight line fitted through it. The large amount of scatter in the relationship is a consequence of the large variance introduced by the uniform distributions.

The per capita birth rate and consequently the realized population growth rate in Murray's simulation model are functions of population density as a direct consequence of the assumptions made by Murray. As a

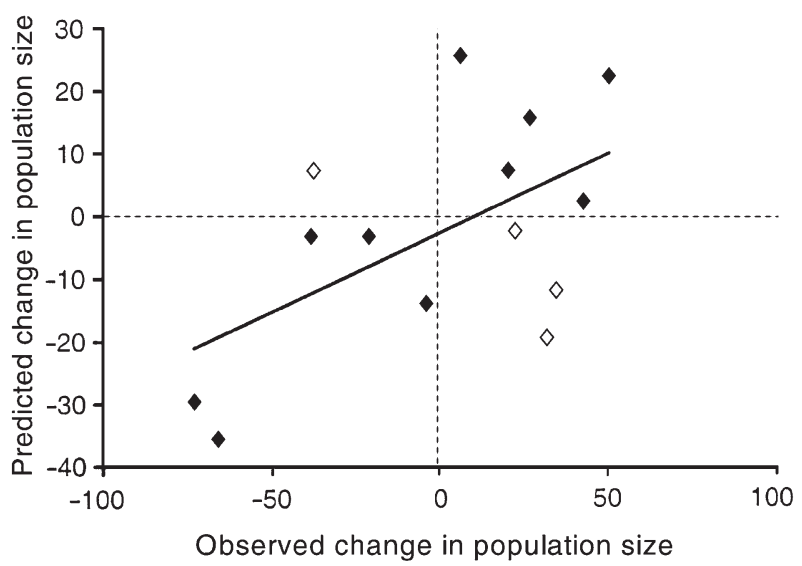

Figure 1. Comparison of predicted and observed changes in population size, $N_{t+1}-N_{t}$, between Murray's 15 years simulation (observed change) and the changes predicted from Equation. 1. Empty symbols indicate observations where the direction of the change was not correctly predicted. 
result the average number of new recruits to the population is always the same, regardless of population density. We cannot see how this can arise without the action of either competition among breeding individuals for resources, or predation risk to newborns that increases with population density, both of which represent negative feedbacks of population density on per capita birth rate. A single breeding individual must be able to produce up to 100 offspring, while a population of 100 breeders can produce no more than one offspring each. We should like to point out that it is perfectly possible to model a process without mentioning it in words, especially if one does not clearly state the ecological mechanisms underlying the assumptions.

To reiterate: the key point on which we differ from Murray about the interpretation of his simulation model is whether or not there is a negative feedback of population density on population growth embedded in the assumptions. He claims there are not: we have demonstrated that there are.

Acknowledgments - We would like to thank B. G. Murray for stimulating us to think critically about density dependence and the relationships between models and mechanisms, Peter Turchin and the PHLEM discussion group for enlightening discussions. The manuscript benefited from critical comments by Clare Bradley, Steve Ball, Ian Ball, Hugh Possingham, B. G. Murray, and Michael Bull. AJT is supported by an ARC SPIRT grant to Hugh Possingham and by WMC (Olympic Dam) Ltd. Pty.

\section{References}

Andrewartha H. G. \& Birch L. C. (1954) The Distribution and Abundance of Animals. University of Chicago Press, Chicago.

Bonsall M. B., Jones T. H. \& Perry J. N. (1998) Determinants of dynamics: population size, stability, and persistence. Trends Ecol. Evol. 13, 174-6.

Murray B. G. Jr. (2000) Dynamics of an age-structured population drawn from a random numbers table. Austral. Ecol. 25, 297-304.

Nicholson A. J. (1933) The balance of animal populations. J. Anim. Ecol. 2, 132-78.

Sokal R. R. \& Rohlf F. J. (1981) Biometry. W. H. Freeman, New York.

Turchin P. (1995) Population regulation: old arguments and a new synthesis. In: Population Dynamics: New Approaches and Synthesis. (eds. N. Cappuccino \& P. W. Price). Academic Press, San Diego, 19-40.

Turchin P. (1999) Population regulation: a synthetic view. Oikos 84, 153-9.

\section{Appendix}

The initial model is

$$
N_{t+1}=S \cdot N_{t}+F
$$

rearranged and placed on a logarithmic scale,

$$
\begin{aligned}
& N_{t+1}=N_{t}\left(S+\frac{F}{N_{t}}\right) \\
& \ln N_{t+1}=\ln N_{t}+\ln \left(S+\frac{F}{N_{t}}\right)
\end{aligned}
$$

and finally,

$$
r=\ln N_{t+1}-\ln N_{t}=\ln \left(S+\frac{F}{N_{t}}\right)
$$

